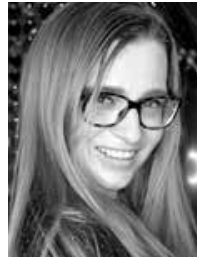

Инна Марахина,

доцент кафедры экономики Белорусского

государственного университета

информатики и радиоэлектроники,

кандидат экономических наук, доцент;

ina_marahina@tut.by

Аннотация. $B$ статье проводится анализ особенностей и отличий субъектов инновационной инфраструктуры системы образования Республики Беларусь, раскрывается их роль в развитии вуза при переходе к модели «Университет 3.0». На основе представленного исследования автор предлагает рекомендации по развитию инновационной инфраструктуры вуза.

Ключевые слова: вузы, Университет 3.0, предпринимательский университет, инновационная деятельность, инновационная инфраструктура.

Для цитирования: Марахина И. Развитие инновационной инфраструктуры вуза при переходе к модели «Университет 3.0» // Наука и инновации. 2020. №12. С. 64-69.

https://doi.org/10.29235/1818-9857-2020-12-64-69.

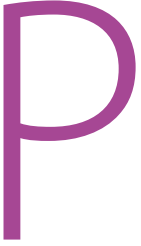

азвитие современных вузов связывают с их переходом к новой модели «Университет $3.0 »$, или предпринимательский университет, который, в отличие от классических, совмещает преподавательскую, научно-исследовательскую и предпринимательскую деятельность и получают от нее доход. Подготовка специалистов в нем нацелена, с одной стороны, на обучение и выпуск поколений инноваторов, с другой на производство инновационных идей и продуктов для разных отраслей экономики $[1,2]$.

В нашей стране о важности такого перехода заговорили сравнительно недавно. А в конце 2017 г. были утверждены Кон- 
цептуальные подходы к развитию системы образования Республики Беларусь до 2020 г. и на перспективу до 2030 г., где внедрение модели «Университет 3.0», которая предполагает создание внутри университетов интегрированной образовательной, научно-исследовательской и предпринимательской среды, было определено в качестве составляющей механизма осуществления поставленных задач в сфере высшего образования до 2020 г. [3]. Начиная с 2018 г. эта концепция реализовывается в 7 вузах: БГУ, БНТУ, БГУИР, БГЭУ, БРУ, ГрГУ, БГТУ в рамках экспериментального проекта «Совершенствование деятельности учреждений высшего образования на основе модели «Университет 3.0» (комплексное развитие научно-исследовательской, инновационной и предпринимательской инфраструктуры учреждения высшего образования в целях создания инновационной продукции и коммерциализации результатов интеллектуальной деятельности)» [4].

Его выполнение предусматривает два направления действий:

внесение изменений и дополнений в учебно-программную документацию образовательных программ высшего образования I ступени, нацеленных на системное взаимосвязанное изучение вопросов инновационной, изобретательской и предпринимательской деятельности (формирование бизнес-среды), и II ступени, стимулирующих реализацию стартапов в бизнес-инкубаторах, командное выполнение высокотехнологичных проектов в рамках практико- и научно-ориентированного обучения; осуществление комплекса мер по созданию субъектов инновационной инфраструктуры (научно-технологические парки, центры трансфера технологий), отраслевых лабораторий, бизнес-инкубаторов, а также повышению эффективности научно-исследовательской, инновационной работы, способствующих на завершающем этапе коммерциализации инновационной продукции и (или) результатов интеллектуальной деятельности [4].

Остановимся подробнее на формировании инновационной инфраструктуры при переходе к «Университету 3.0». Под ней будем понимать совокупность взаимосвязанных структур и субъектов вуза, обеспечивающих инновационный процесс, в том числе инициацию, условия и ресурсы и непосредственно осуществление научной и инновационной деятельности, а также коммерциализацию и трансфер ее результатов.

Следует отметить, что согласно Закону Республики Беларусь «О государственной инновационной политике и инновационной деятельности в Республике Беларусь» к ним относятся научно-технологические парки (технопарки), центры трансфера технологий, венчурные организации [5]. Однако автором использован подход, согласно которому в данный перечень входят и другие подразделения вуза, деятельность которых направлена на осуществление и обеспечение инновационного процесса, к примеру бизнес-инкубаторы и отраслевые лаборатории. В интервью первый заместитель министра образования Беларуси И.А. Старовойтова отмечает, что «в 2018 г. инновационная инфраструктура вузов Министерства образования в целом пополнилась 8 отраслевыми лабораториями для решения задач машиностроения, здравоохранения и химической отрасли, финансовой и налоговой сферы. Таким образом, в ее состав входят 17 отраслевых лабораторий, 6 научно-технологических парков и 2 центра трансфера технологий. Прорабатываются вопросы об открытии еще двух отраслевых лабораторий на базе БГУИР и Гродненского государственного университета имени Я. Купалы» [6].

Рассмотрим названные субъекты инновационной инфраструктуры для вузов, участвующих в экспериментальном проекте, и их роль при переходе к модели «Университет 3.0».

\section{Отраслевые лаборатории}

Согласно Примерному Положению об отраслевой лаборатории под ней понимается подразделение, создаваемое в структуре научной организации для выполнения НИОКР, научного сопровождения инновационных проектов, опытно-промышленной апробации и внедрения в производство результатов научной и научно-технической деятельности в организациях профильной области или отрасли, осуществляющее свою деятельность на основе плана совместных работ с республиканскими органами государственного управления и иными государственными организациями, подчиненными Правительству Республики Беларусь, Национальной академии наук Беларуси, реализующими госу- 
дарственную политику в соответствующей сфере [7]. Такие лаборатории, как правило, являются структурной единицей вуза (например, входят в его научно-исследовательскую часть), курируются руководителем научной организации или его заместителем и имеют достаточно большую хозяйственную самостоятельность.

При переходе к модели «Университет 3.0» отраслевые лаборатории выполняют следующие функции:

- активизацию научной и инновационной деятельности в вузе;

- привлечение к ней обучающихся и сотрудников учебного заведения;

- создание и внедрение новых методов исследований;

- реализацию образовательных программ, соответствующих пробилю отраслевой лаборатории в части интеграции практической подготовки и научных исследований;

- внедрение научных результатов в производство, учебный прочесс, их коммерииализацию;

- предоставление оборудования, персонала для выполнения НИОКР, научного сопровождения инновационных проектов, апробации практического использования разработок;

- укрепление связей с производством и реальной экономикой, развитие предпринимательства [7-10].

В БГУИР марте 2019 г. на базе научно-образовательного инновационного центра СВЧ-технологий и их метрологического обеспечения (Центр 1.9) создана отраслевая лаборатория. Основными направлениями ее деятельности являются научные исследования, создание новых изделий и технологий, методов и методик, прецизионных измерений, стандартных испытаний измерительной техники миллиметрового диапазона длин волн по совместным планам с государственным заказчиком; проведение НИОКР, в том числе по разработке новых и совершенствованию существующих методов радиолокации, новых типов радиотехнического оборудования, аппаратно-программных средств и устройств различного назначения; организация, проведение и участие в выставках, семинарах, конференциях и обучающих курсах для обмена опытом, повышения квалификации научных работников и специалистов [8].

С целью укрепления научных связей БГЭУ с Министерством антимонопольного регулирования и торговли Республики Беларусь (МАРТ) с января 2019 г. на базе кафедры экономики торговли и услуг факультета коммерции и туристической индустрии функционирует отраслевая лаборатория антимонопольного и ценового регулирования, регулирования в области торговли. План ее совместных работ с Министерством образования Республики Беларусь включает научное сопровождение деятельности МАРТ, участие в научных и практических конференциях, семинарах, круглых столах, прочих мероприятиях, проводимых на базе БГЭУ и МАРТ, организацию тематических круглых столов, популяризацию итогов научных исследований в области антимонопольной и ценовой политики, оказание консультативной и практической помощи, осуществление экспериментальной и инновационной деятельности в сфере образования на основе модели «Университет 3.0» [9].
Создана также отраслевая лаборатория актуальных проблем налогообложения и налоговой политики БГЭУ.

Наибольшее количество отраслевых лабораторий функционирует в БГТУ. Это Инжиниринговый центр по апробации наноматериалов в нефтехимическом и промышленном комплексах, Отраслевая лаборатория шинной промышленности, Отраслевая лаборатория наукоемких технологий целлюлозно-бумажной и лесохимической промышленности, производства древесных плит и пластиков, Научная отраслевая лаборатория технологических процессов деревообработки и проектирования мебели, Отраслевая лаборатория по переработке фосфатного сырья, Научная отраслевая лаборатория защиты леса, Отраслевая лаборатория проектирования, строительства и эксплуатации лесных автомобильных дорог, Отраслевая лаборатория стекла и стекловидных материалов, Отраслевая лаборатория стекла и волокнистых материалов БГТУ.

Два таких субъекта работают в БГУ: в Институте прикладных физических проблем им. А.Н. Севченко - Отраслевая лаборатория «Элионика - радиационностойкая и космическая электроника», в Институте ядерных проблем - Отраслевая лаборатория радиационной безопасности, и 3 в БНТУ: Отраслевая научно-исследовательская лаборатория «Инновационная энергетика», Отраслевая научно-исследовательская лаборатория плазменных и лазерных технологий и Отраслевая лаборатория спортивной биомеханики Научно-технологического парка «Политехник» [10]. 


\section{Научно-технологические парки}

Это субъекты инновационной инфраструктуры со среднесписочной численностью работников до 100 человек, целью которых является содействие развитию предпринимательства в научной, научнотехнической, инновационной сферах и создание условий для осуществления юридическими лицами и индивидуальными предпринимателями - резидентами технопарка - инновационной деятельности [5]. Следует отметить, что вузовские технопарки входят в состав университета, а вот их резиденты это самостоятельные субъекты хозяйствования, чья деятельность соответствует ряду требований. Работа в вузовском технопарке стимулируется следующим образом:

- налоговыми льготами; - предоставлением по льготным иенам или на безвозмездной основе в пользование помещений, оборудования и инбормации;

- дополнительными услугами, ориентированными на научные и инновачионные организации (иентры коллективного пользования оборудованием, консалтинговые услуги, помощь в поиске инвесторов и продвижении продукиии, доступ к партнерской сети по всему миру и т.д.). Отметим комплекс услуг для «выращивания» бизнеса: консалтинг в сферах бизнес-планирования, предпринимательской и инновационной деятельности, управления и коммерииилизации интеллектуальной собственно- сти, разработки и реализаиии комплекса маркетинга; подготовку бизнес-планов; проведение оценки эффективности инновационных проектов; маркетинговых и патентных исследований; почск источников финансирования и содействие в его привлечении. Научно-технологические парки имеют решающее значение в развитии вуза при переходе к модели «Университет $3.0 »$ :

- содействуют развитию предпринимательства в научной, научно-технической, инновачионной сберах, открьтию инновационных производств, малых предприятий, временных творческих коллективов и ведению ими самостоятельной инновационной деятельности;

- создают условия, в том числе социального обеспечения, для высокопроизводительного труда вузовских ученых, закрепления талантливой молодежи в науке и наукоемком производстве, открытия новых рабочих мест;

- ускоряют коммерииализацию результатов научной и инновационной деятельности;

- способствуют осуществлению внешнеэкономической деятельности в иелях продвижения на внешний рынок инновационной продукиии, участию в научно-технических мероприятиях и их организаиии;

- популяризируют научную и инновационную деятельность;

- занимаются подбором белорусских и зарубежных партнеров и оптимальных вариантов сотрудничества, содействуют заключению контрактов;

- привлекают потенииальных инвесторов - заказчиков инновациц, а также финансирование для инновационных проектов и стартапов;

- проводят обучение в области предпринимательства и т.д. [5, 11-14].

Первый и крупнейший университетский технопарк в нашей стране - «Политехник» в БНТУ [13]. К направлениям его исследований и инновационной деятельности относятся: медицина, покрытия и обработка поверхностей, информационные технологии, литье и металлургия, весоизмерение и дозирование, лазерные технологии, дорожные покрытия, строительство, легкая промышленность, экология и энергосбережение. В сферу интересов Научно-технологического парка УП «Унитехпром БГУ» входят химический синтез и продукты; медицина и фармация; электроника и фотоника; агропромышленный комплекс и продовольственная безопасность [12]. В Гродненском государственном университете функционирует еще один технопарк - «УНПЦ Технолаб» [14].

\section{Центры трансфера технологий}

ЦТТ представляют собой организации со среднесписочной численностью работников до 100 человек или обособленные подразделения с не менее 7 сотрудниками, которые обеспечивают передачу инноваций из сферы их разработки в практику. Такие субъекты инновационной инфраструктуры осуществляют перма- 
нентное проведение исследований конъюнктуры рынка по выявлению возможностей реализации инноваций; создают и развивают информационные ресурсы о разработках и ведущихся исследованиях в вузе; консультируют по вопросам финансирования инновационной деятельности.

Роль ЦТТ в развитии вуза при переходе к модели «Университет 3.0» состоит в:

- coдействии передаче и коммерииализаиии технологиц, знаний, навыков, методов в сберь производства и оказании услуг между университетами, предприятиями и другими организациями;

- помоци в продвижении результатов научной и инновационной деятельности и в правовой зашите объектов интеллектуальной собственности;

- привлечении партнеров и клиентов, развитии сотрудничества разработчиков, инвесторов, производителей и потребителей наукоемкой продукиии (продуктов, технологий, услуг) $[5,11,15]$.

В отечественных учреждениях образования работает пока один центр трансфера технологий - в Гродненском государственном университете имени Янки Купалы [15].

\section{Бизнес-инкубаторы}

Это субъекты инновационной инфраструктуры, содействующие организации и осуществлению предпринимательской деятельности на начальных стадиях проекта за счет предоставления помещений офисного назначения и оказания консультационных, бухгалтер- ских, юридических, образовательных и прочих услуг по договорам или безвозмездно. Отличие вузовских бизнес-инкубаторов состоит в том, что они не являются отдельными юридическими лицами и значительную часть услуг предоставляют бесплатно (например, на конкурсной основе). В первую очередь такие структуры ориентированы на обучающихся и активно работают с физическими лицами и командами на ранних стадиях инновационного процесса.

Бизнес-инкубаторы осуществляют обучение предпринимательству и воплощение знаний в практику, проведение стартап-школ, семинаров и т.д.; выращивание стартапов: помощь в создании инновационных предприятий, содействие в финансовом планировании, поиске команды, привлечении инвестиций $[8,16,17]$.

В отечественных вузах также работают бизнес-инкубаторы. Один из них открыт в БГУИР студенческий инновационный Центр профессионального развития $[8,16]$. Для реализации отобранных на конкурсной основе проектов на безвозмездной основе предоставляются оборудованные компьютерами и оргтехникой офисные помещения; консалтинг в области юриспруденции, патентного, налогового законодательства, а также оценки правомочности и обоснованности требований потенциальных бизнес-партнеров и заинтересованных лиц; поддержка специалистов при составлении документов для получения инвестиций; возможность демонстрации лучшей научной продукции на отечественных и зарубежных выставках, конференциях и прочих мероприятиях; спонсорская помощь от университета и различных компаний для первичного развития и продвижения разработок. Кроме того, на базе бизнес-инкубатора регулярно проводятся стартап-школы, хакатоны, мастер-классы, обзорные лекции и встречи с бизнесменами - руководителями крупных компаний.

Бизнес-инкубатор БГЭУ ставит перед собой задачу превратить идею студентов (магистрантов, аспирантов) университета в проект, а затем в бизнес, приносящий реальный доход. Для этого оказывается содействие в коммерциализации проекта, разработке бизнес-модели, определении рынка продукта, подготовке программы продвижения, маркетинговой и рекламной стратегии, помощь в проведении маркетинговых исследований; проводится консультирование по вопросам кредитования, налогообложения, бухгалтерского учета, правовой защиты и развития предприятия (проекта); бизнес-планирование будущей предпринимательской деятельности и ее внешнее бухгалтерское обслуживание. Дополнительно предоставляются юридические, переводческие услуги; организовываются социальные проекты, психологическое консультирование, оказывается помощь в проведении бизнес-форумов, семинаров и выставок с целью продвижения продукции и технологий на рынок и поиска внутренних и внешних инвесторов; повышение образовательного уровня учащихся в сфере предпринимательской деятельности. Срок поддержки реализации проектов - до 1 года в зависимости от их сложности [17]. 


\section{Другие субъекты инновационной инфраструктуры}

Один из таких субъектов, активно развивающийся в последнее время, - центр коллективного пользования оборудованием, который не только обеспечивает доступ к уникальным научным установкам, но и повышает престиж университета, позволяет активизировать научно-инновационное сотрудничество.

Кроме того, во многих вузах функционируют клубы, школы и центры молодежного предпринимательства, где обучают основам бизнеса, маркетинга, поиска инвесторов, создания команд, проводят конкурсы и знакомят с потенциальными партнерами.

Таким образом, проведенный анализ показал, что практически все рассмотренные субъекты инновационной инфраструктуры вузов ориентированы на поддержку научной и инновационной деятельности своих студентов и сотрудников с учетом особенностей и специфики учреждения образования на разных стадиях инновационного процесса. При этом каждое из таких подразделений имеет свои особенности и функции, и одновременное их наличие в рамках одного вуза не излишне, а наоборот, обеспечивает синергетический эффект. Однако не в каждом университете, участвующем в экспериментальном проекте, представлены инновационные субъекты, например из 7 вузов только в одном создан центр трансфера технологий. Поэтому считаем важным активизировать работу в этом сегменте с учетом следующих направлений:
- образование в каждом вузе субъектов инновационной инфраструктуры всех рассмотренных видов, поддержка их развития;

- активное инбормирование об их работе как внутри вуза, так и за его пределами;

- ориентация на реализацию интеллектуального потенииала максимального числа сотрудников и обучающихся, их привлечение к научной и инноваицонной деятельности;

- развитие вузовской системы научной и технической информации;
- обеспечение преемственности и взаимодействия между субъектами инновационной инфраструктуры, а также с подразделениями вуза (отделом маркетинга, бухгалтерией, библиотекой и т.д.). Скорейшая реализация предложений позволит сформировать благоприятные условия для развития предпринимательского климата в вузах, коммерциализации результатов интеллектуальной деятельности и осуществления остальных мероприятий, заложенных в рамках перехода к модели «Университет 3.0».m

- Summary. One of the most promising ways to develop higher education institutions is University 3.0 (or an entrepreneurial university). Such a model is being introduced in seven Belarusian universities as part of a pilot project. The key direction in the transition to the models «University 3.0 » is the creation of innovative infrastructure facilities, including science and technology parks, technology transfer centers, industry laboratories, and business incubators. In the article, the author analyzes the subjects of innovation infrastructure - the structure of Belarusian universities, reveals the role of such subjective factors in the development of models «University 3.0». Based on the presented research, the author offers recommendations on the development of the university's innovative infrastructure.

Keywords: University 3.0, entrepreneurial university, innovative activity, innovative infrastructure, science and technology park, technology transfer center, industry laboratory, business incubator. https://doi.org/10.29235/1818-9857-2020-12-64-69

\section{СПИСОК ИСПОЛЬЗОВАННЫХ ИСТОЧНИКОВ}

1. Андрюшкевич 0.А. Формирование предпринимательских университетов в инновационной экономике / 0.А. Андрюшкевич, И.М. Денисова // Экономическая наука современной России. 2014. №3 (66). С. 87-104.

2. Марахина И.В. Коммерциализация результатов научно-технической деятельности в условиях перехода вузов к модели «Университет 3.0» // Высшая школа: проблемы и перспективы: сборник материалов XIV Междунар. науч.-метод. конф., Минск, 29 ноября 2019 г. / Акад. управления при Президенте Республики Беларусь. - Минск, 2019. С. $91-93$.

3. Концептуальные подходы к развитию системы образования Республики Беларусь до 2020 года и на перспективу до 2030 года // https://edu.gov.by/sistema-obrazovaniya/glavnoe-upravlenie-professionalnogoobrazovaniya/prof-obr/respublikanskyi-sovet-direktorov-uchrezhdeniy-professionalno-tekhnicheskogo-isrednego-spetsialnogo.

4. Экспериментальный проект «Совершенствование деятельности учреждений высшего образования на основе модели «Университет 3.0» (комплексное развитие научно-исследовательской, инновационной и предпринимательской инфраструктуры учреждения высшего образования в целях создания инновационной продукции и коммерциализации результатов интеллектуальной деятельности). Описание экспериментального проекта // http://nihe.bsu.by/index.php/2opisanie-eksperimentalnogo-proekta.

5. О государственной инновационной политике и инновационной деятельности в Республике Беларусь: Закон Республики Беларусь от 10 июля 2012 г. №425-3 // https://www.pravo.by/document/?guid=3871\&p0 $=\mathrm{H} 11200425$.

Полный список использованных источников размещен 口 SEE http://innosfera.by/2020/12/university_3.0 